\title{
Synchronous Boost Converter with High Efficiency at Light Load using QSW-ZVS and SiC MOSFETs
}

\author{
Alberto Rodriguez, Member, IEEE, Aitor Vazquez, Member, IEEE, Maria R. Rogina, Student \\ Member, IEEE, Fernando Briz, Senior Member, IEEE.
}

\begin{abstract}
A converter intended to be used for the interconnection of battery based energy storage systems with the cells of a multilevel converter is addressed in this paper. High efficiency at light and medium loads is important in these applications and it can be achieved using soft switching techniques. Two control techniques with fixed and variable switching frequency are proposed and compared. The use of SiC MOSFETs provides a higher attainable switching frequency, which is especially interesting in variable frequency control techniques, allowing the operation at high voltages and high switching frequencies, with high efficiencies over a wide power range. A synchronous boost DC/DC converter rated for $400 \mathrm{~V}$ to $800 \mathrm{~V}$ and $10 \mathrm{~kW}$ is designed and developed with SiC MOSFETs obtaining efficiencies higher than $97 \%$ from $100 \%$ to $3.5 \%$ of full load using a variable switching frequency (up to $200 \mathrm{kHz}$ ) control. Significant efficiency improvement is achieved at medium and light loads.
\end{abstract}

Index Terms- DC/DC bidirectional converters, QSWZVS, TCM, light load operation, SiC MOSFETs.

\section{INTRODUCTION}

$\mathrm{P}_{\mathrm{s}}$ OWER Electronics Transformers (PETs), also called Solid State Transformers (SSTs) have been proposed as a semiconductor based alternative to conventional LineFrequency Transformers LFTs [1]. PETs are expected to beat the LFTs in terms of power density and much superior functionalities, but would be inferior in terms of cost, efficiency (full load) and reliability [1]-[4]. A fully modular three stage approach $(\mathrm{AC} / \mathrm{DC}+\mathrm{DC} / \mathrm{DC}+\mathrm{DC} / \mathrm{AC})$ appears to be the most popular choice [2], [5]-[9]. Based on the modular approach, the use of multilevel converters to develop the AC/DC stage of the PET is very common, as in the case CHB-based PET [9] and MMC-based PET [10], [11]. Multilevel converters have several convenient characteristics [12]-[16], being a distinguishing one the fact that while it provides a high voltage DC link, the distributed energy storage at the cells capacitors eliminates the need of a bulk DC capacitor, which is advantageous for safety and reliability reasons [17].

In PETs based in multilevel converters, it is possible to add, by adequate design of the cells, a multiport capability, able to

This work was supported by the European Commission under the Seventh Framework Programme, project NMP3-LA-2013-604057 and by the Spanish Government under projects DPI2013-47176-C2-2-R and DPI2014-56358-JIN, student grant BES2014-070785, and through funding from the Government of Asturias through the project FC-15-GRUPIN14-143 and FEDER funds.

The authors are with University of Oviedo, Department of Electrical, Computer and Systems Engineering, Campus de Viesques s/n, 33204 Gijon, SPAIN (e-mail: rodriguezalberto@uniovi.es). integrate at the cell level low voltage dc or ac power sources (such as PV panels or wind turbines), loads or energy storage devices. The inclusion of distributed energy storage capability can be carried out integrating storage systems at the cell level. However, if the voltage value at the cell and the storage system are different, the use of bidirectional power converters is mandatory to adapt the energy format.

High efficiency is paramount importance in PETs, and is therefore also demanded to any electronic power converter integrated into the PET. Battery charging process is usually done in three stages [18], with a final stage in which the charging current is very low. The power converter connecting the battery with the PET cell should therefore provide high efficiency over a wide power range.

This paper proposes a variable switching frequency (which can be as high as $200 \mathrm{kHz}$ for low power levels at light loads) control technique for this purpose. The cell voltage being considered is $800 \mathrm{~V}$. To comply with the high voltage and switching frequency requirements, the use of Silicon Carbide (SiC) MOSFETs is proposed. As it is already known new wide band-gap (WBG) semiconductors, especially $\mathrm{SiC}$ or Gallium Nitride $(\mathrm{GaN})$ transistors can withstand higher voltage levels, allowing faster switching and having lower conduction losses, in comparison with similar silicon-based transistors [19]. The validation of the use of SiC MOSFETs, allowing an increase in the maximum achievable switching frequency, together with a variable switching frequency control technique to operate at high voltage, high frequency and obtaining high efficiency in a synchronous boost converter, especially at medium and light load, is the main contribution of this paper.

This paper is organized as follows. The system overview is presented in Section II. Section III discusses operation and control principles of the synchronous boost, with special focus on the efficiency at light loads. Experimental results are presented in Section IV, the conclusions being summarized in Section V.

\section{SYSTEM DESCRIPTION}

A potential configuration for a three-stage multiport PET is derived from the MMC topology, where an isolated and bidirectional DC/DC converter (being a Dual Active Bridge (DAB) usually preferred) is used to inject/drag power from the MMC cells. The low voltage (LV) side of the DABs are parallelized to form a low-voltage, high-current DC link [10], [11]. The MMC-based PET provides three ports: high-voltage DC (HVDC), high-voltage AC (HVAC) and low-voltage AC 
(LVAC), being therefore a multiport power converter where all the ports are bidirectional.

In the configuration discussed in [11], all the MMC cells are parallelized via DABs to form a full power-low voltage DC bus. It is possible however to connect elements to the DC link of the cells. These can include energy storage elements [20] or distributed energy resources (DER) [21]. This is schematically shown in Fig. 1. In this case, part of the cells are connected in parallel using DABs to perform the AC/AC power conversion with galvanic isolation and other cells are connected to energy storage elements and DER using non isolated DC/DC power converters. The converter connecting the DER/energy storage to the MMC cell does not have to be necessarily a DAB, it can be optimized for the specific needs (e.g. galvanic isolation or bidirectional power flow capability).

Although the converter presented in this work is oriented to provide DER, especially energy storage capability, to a MMCbased PET, the conclusions can be applied to different applications where a bidirectional converter with high efficiency for light loads and high voltage operation is needed (e.g. wind energy generation with storage capability [22] or electric vehicle (EV) battery chargers [23], [24]).

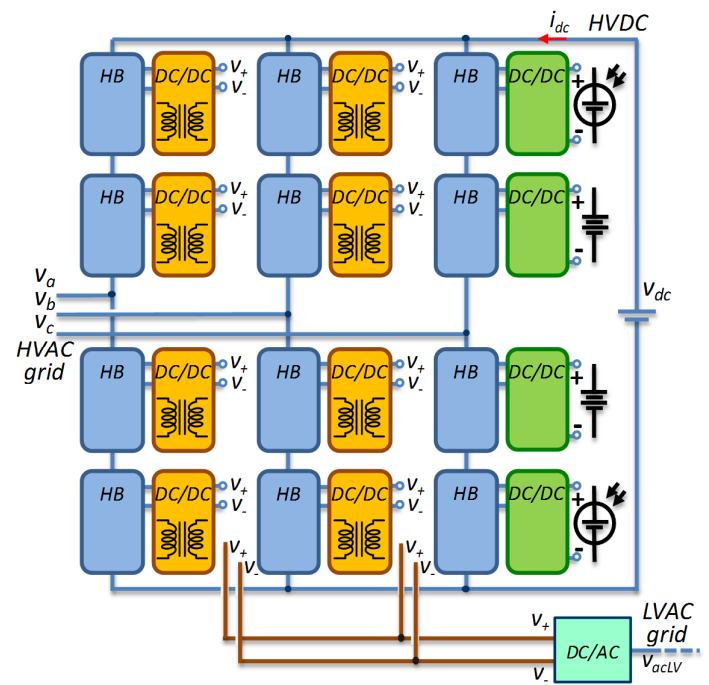

(a)

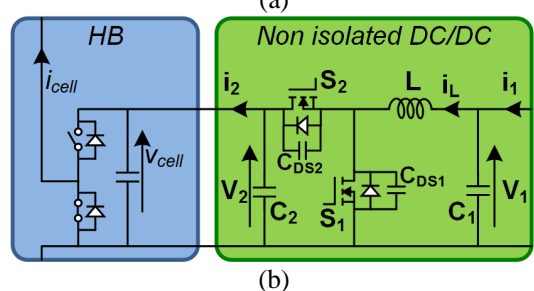

(b)

Fig. 1. (a) DER and/or energy storage integration in a MMC. (b) Structure of the cell with distributed energy storage systems.

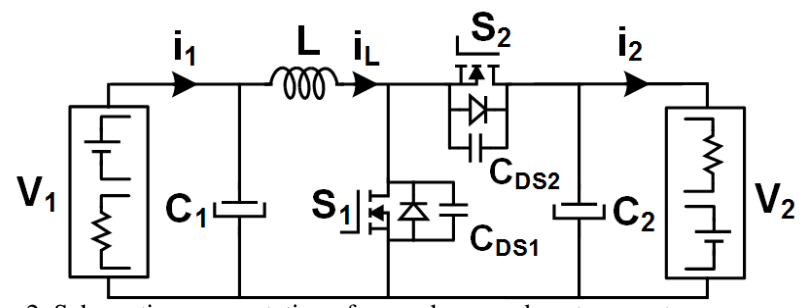

Fig. 2. Schematic representation of a synchronous boost converter.

\section{QSW-ZVS MODE FOR SYNCHRONOUS BOOST CONVERTER AND DESIGN GUIDELINES}

\section{A. TCM and QSW-ZVS operational modes}

The synchronous boost converter (see Fig. 2) is the bidirectional DC/DC topology without galvanic isolation using the lowest number of power devices. A number of control strategies have been proposed for this topology. The converter can work in discontinuous conduction mode (DCM) with one of the transistors turned-off, being its parasitic body diode the freewheeling diode. In applications using Si MOSFET with voltage higher than $400 \mathrm{~V}$, DCM is normally avoided, because of the increased losses due to the poor characteristics of the $\mathrm{Si}$ MOSFET body diodes. Alternatively, the converter can work in continuous conduction mode (CCM) with both transistors switching and their body diodes conducting the current only during dead times.

Three different modes can be used with CCM, depending on the inductance value (or the inductance current ripple) and the switching frequency:

1) CCM hard switching (CCM-HS). It uses a large inductance, consequently showing a reduced current ripple, and operates at a constant switching frequency;

2) Triangular Current Mode (TCM). A low inductance and consequently large current ripple occur in this case, the switching frequency also remaining constant;

3) quasi-square wave mode with soft switching (QSW-ZVS). This mode is characterized by a low inductance and therefore large current ripple, the switching frequency being variable in this case.

The main characteristics of each mode of operation are summarized in TABLE I.

The key advantage of CCM-HS mode is the low current ripple through the inductor. This makes CCM-HS suitable for its use with energy storage systems, as it prevents aging as well as derating during the charging and discharging processes. However, the price to pay are the increased switching losses, which are dominant in this mode of operation, and compromise the overall efficiency of the converter.

To reduce the switching losses, TCM (also known as QSWZVS at constant switching frequency) can be used with traditional DC/DC topologies (buck, boost and buck-boost converter families) [25]-[28]. In this mode of operation, the duty cycle is close to $50 \%$, the dead times being used to achieve Zero Voltage Switching (ZVS) and Zero Current Switching (ZCS). The efficiency of QSW-ZVS can then defeat that of CCM-HS, especially in applications with dominant switching losses.

To achieve full ZVS using TCM, $\mathrm{V}_{2}$ must be at least twice $\mathrm{V}_{1}$ when the power flows in "boost direction", while $\mathrm{V}_{1}$ must be higher than half $\mathrm{V}_{2}$ when the power flows in "buck direction" [29]. Consequently, only when $V_{2}$ is twice $V_{1}$, ZVS can be achieved using TCM in both power flow directions.

Furthermore, the inductance value must be small, as a large current ripple is required to obtain negative current during the commutation. The ideal waveforms of a synchronous boost converter working in TCM mode can be seen in Fig. 3. Four regions are observed during each switching period $(T)$ : the 
magnetizing interval $\left(t_{o n}\right)$, the demagnetizing interval $\left(t_{o f f}\right)$, and two dead times $\left(t_{d 1}\right.$ and $\left.t_{d 2}\right)$.

The on-time and off-time regions are known as linear intervals, while both dead time regions are known as resonant intervals. The lower limit for the first dead time $\left(t_{d 1}\right)$ is constrained by the need to avoid a short-circuit when $S_{2}$ is turned on and $S_{1}$ is turned off. On the other hand, excessive large values of $t_{d 1}$ will result in increased losses in the parasitic body diode of $S_{2}$. During the second dead time $\left(t_{d 2}\right)$ the inductance current becomes negative, forming a resonant circuit with the parasitic output capacitance of the transistors. Due to the resonance, $S_{1}$ output capacitance can be discharged and ZVS can be achieved when $S_{1}$ is turned on. Moreover, $S_{2}$ is turned off with Zero Current Switching (ZCS), the overall switching losses reducing drastically. Dead time $t_{d 1}$ has little importance and is neglected in most of the studies on QSWZVS, only the interval $t_{d 2}$ being considered for ZVS [27].

TCM presents two major disadvantages when used in battery storage systems. First, the large current ripple in the inductance is undesirable for the battery. This drawback can be overcome by using modular converters (i.e. multi-phase interleaved converters connected in parallel). Second, relatively large values of the reactive current can occur in the ZVS mode when the converter operates at light loads. This is due to the fact that the average current is reduced while the current ripple remains constant in this case. Consequently, at light loads the converter works with more reactive current than is actually needed to achieve ZVS. This is illustrated in Fig. 4(b). This second disadvantage severely compromise the efficiency with light loads, which is a significant drawback for battery management applications. CCM-HS has been included in Fig. 4(a) only for comparison purposes.

Alternatively to TCM, QSW-ZVS can be used. Both methods respond to the same principles, but the second operates at a variable switching frequency [29]-[34]. In QSW-ZVS, the switching period is adapted to guarantee that the converter works with the smallest amount of reactive current needed to achieve ZVS. With light loads, QSW-ZVS increases the switching frequency to maintain the minimum current constant, the reactive current remaining invariant with respect to the full load condition, consequently improving efficiency of TCM. Ideal inductance current waveforms for QSW-ZVS operation and different power ratios can be seen in Fig. 4(c).

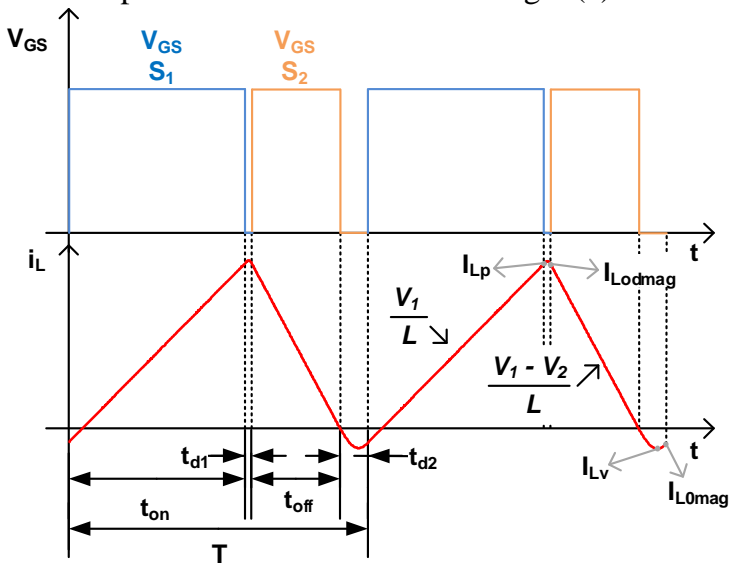

Fig. 3. Ideal waveforms of a synchronous boost converter working in QSWZVS mode.

\section{B. TCM and QSW-ZVS design guidelines}

As an example, both TCM and QSW-ZVS have been designed and compared for input and output voltages of $400 \mathrm{~V}$ and $800 \mathrm{~V}$ respectively, and a maximum power of $10 \mathrm{~kW}$. These specifications are typical in high-voltage battery charger applications, as stated in Section I. The minimum switching frequency was chosen to tradeoff switching losses and audible noise, a switching frequency of $20 \mathrm{kHz}$ was selected. It is noted that while TCM uses constant frequency, QSW-ZVS varies the frequency inversely proportional to the output power. Boundary Conduction Mode is assumed at the maximum power of $10 \mathrm{~kW}$. For this power ratio, the inductance is obtained as [35]. Where $D$ is the duty cycle, $P$ is the power, $V_{1}$ is the input voltage and $f_{s}$ is the switching frequency. For the operating condition defined above, the inductance provided by (1) is $200 \mu \mathrm{H}$.

$$
L=V_{1}^{2} \cdot \frac{D}{2 P} \cdot \frac{1}{f_{S}}
$$

The minimum inductive current needed for ZVS condition (2) is obtained by matching the energy stored in the inductance and the energy stored in the output parasitic capacitor during the dead time (second resonant period).

$$
I_{L v}=-V_{2} \sqrt{\frac{C_{s w}}{L}}
$$

where $V_{2}$ is the output voltage, and $C_{S w}$ is the equivalent parasitic capacitor of the switching node, which is twice the output parasitic capacitor of each MOSFET transistor.

The theoretical maximum and minimum inductance current vs. load are shown in Fig. 5 (the main specifications of the boost converter are shown in TABLE II). It is seen from the figure that the minimum inductance current is always lower for TCM than for QSW-ZVS, which implies more reactive power. Fig. 6 shows the ratio between the average reactive and active powers for both modes of operation as a function of the load. The higher the ratio is, the larger are the expected power losses due to the reactive power. It is observed from the figure that for low and medium loads, TCM has always a ratio higher than $40 \%$, and it increases to near $80 \%$ when the converter works at $1 \mathrm{~kW}(10 \%$ of the rated power). On the other hand, QSW-ZVS has a ratio below $10 \%$ with medium loads, and near $20 \%$ at $1 \mathrm{~kW}(10 \%$ of the rated power). It is concluded from this analysis that the efficiency of QSW-ZVS mode at light and medium load levels is expected to be higher than for TCM.

Nevertheless, QSW-ZVS mode also has some disadvantages. As has been previously explained, when $V_{2}$ is not twice $V_{1}$, full ZVS cannot be achieved for both power flow directions, which can limit the application fields. However, even when $V_{2}$ is not exactly twice $V_{1}$, switching losses can be greatly reduced (thanks to partial ZVS) [36] and efficiency at medium and light loads can be considerably increased. Moreover, variable switching frequency operation increases the electromagnetic emissions (EMI), which can be a problem in applications in which EMI regulations are restrictive. Larger EMI filters can be required in this case, increasing the overall weight, volume and cost of the converter. 
TABLE I

CCM OPERATIONAL MODES COMPARISON

\begin{tabular}{cccccc}
\hline \hline Operational Mode & $\begin{array}{c}\text { Dominant } \\
\text { losses }\end{array}$ & $\begin{array}{c}\text { Inductance } \\
\text { current ripple }\end{array}$ & $\begin{array}{c}\text { Switching } \\
\text { frequency }\end{array}$ & Pros & Cons \\
\hline CCM-HS & Switching & Very low & Constant & $\begin{array}{c}\text { Simplicity } \\
\text { Low current ripple }\end{array}$ & Efficiency \\
\hline TCM & Conduction & Very high & Constant & Efficiency at full load & $\begin{array}{c}\text { Reactive current at light load } \\
\text { Current ripple }\end{array}$ \\
\hline QSW-ZVS & Conduction & High & Variable & Efficiency & Current ripple \\
EMI
\end{tabular}

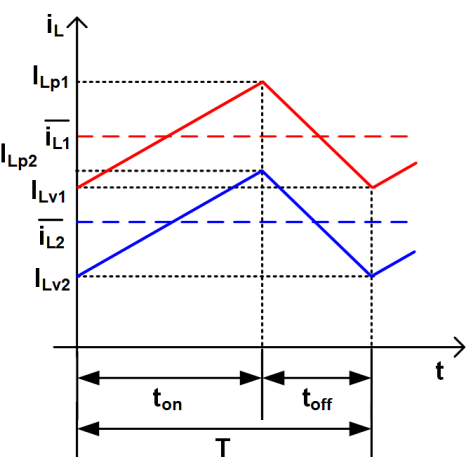

(a)

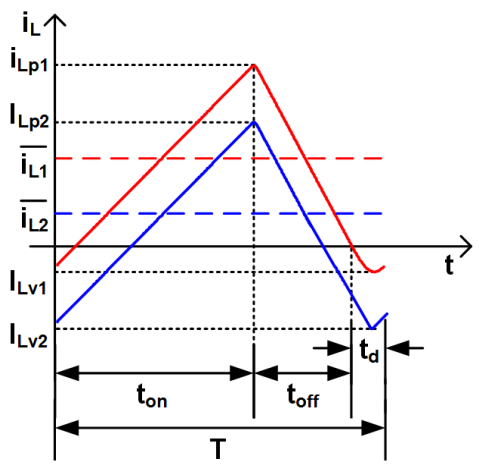

(b)

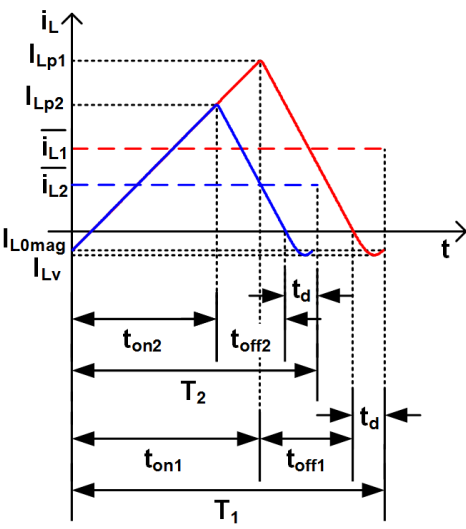

(c)

Fig. 4. Inductor current waveform for two different power levels. (a) CCM-HS. (b) TCM. (c) QSW-ZVS. Inductance value of $600 \mu \mathrm{H}$ for CCM-HS and 200 $\mu \mathrm{H}$ for TCM and QSW-ZVS.

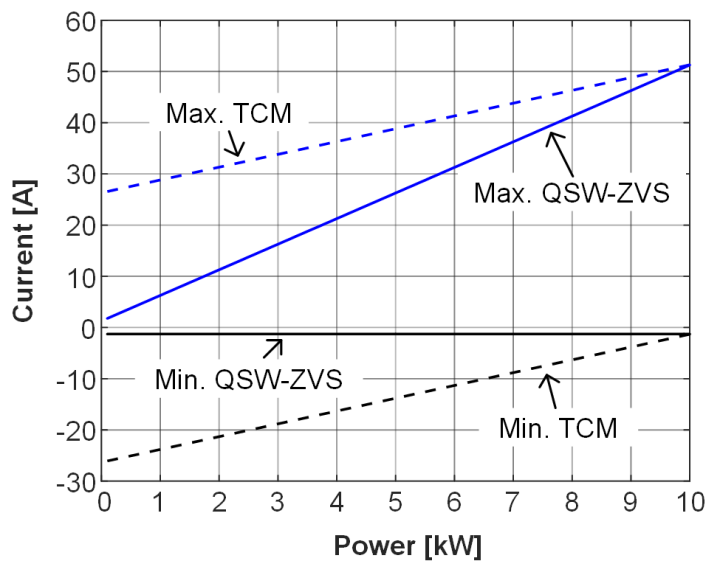

Fig. 5. Maximum and minimum inductance current vs. power for TCM and QSW-ZVS modes.

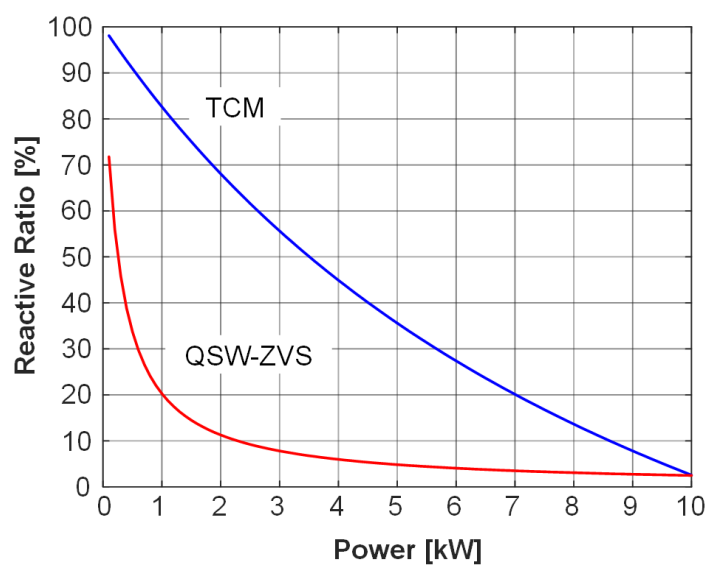

Fig. 6. Active to reactive ratio vs. power for TCM and QSW-ZVS modes.
It must also be considered for QSW-ZVS that the switching frequency cannot be unlimitedly increased due to component limitations. In Fig. 7 the theoretical variation of the switching frequency of QSW-ZVS mode is shown as a function of the power, it is seen to decrease with the output power. While for full load operation the switching frequency remains close to the nominal value of $20 \mathrm{kHz}$, for loads below $500 \mathrm{~W}$ ( $5 \%$ of the rated power), it varies in range between $150 \mathrm{kHz}$ and $300 \mathrm{kHz}$. The maximum switching frequency is mainly limited by the output capacitance of power transistors. This parasitic capacitance affects to the switching times required to obtain ZVS, and plays an important role when the switching frequency increases. The maximum switching frequency of the power devices $f_{\text {smax }}$ determines the minimum power for QSW-ZVS (3).

$$
P_{\text {min }}=V_{1}^{2} \cdot \frac{D}{2 L} \cdot \frac{1}{f_{\text {smax }}}
$$

Thanks to the low parasitic capacitances of SiC MOSFETs, $f_{\text {smax }}$ can be greatly increased, allowing the use of QSW-ZVS for very light loads.

\section{Device selection and TCM and QSW-ZVS theoretical efficiency comparison}

In low voltage applications (up to $400 \mathrm{~V}$ ), the use of $\mathrm{Si}$ MOSFETs allows the use of switching frequencies around hundreds of kHz. For voltages above $600 \mathrm{~V}$, Si IGBT transistors might be needed. Unfortunately, IGBTs cannot operated at switching frequencies exceeding a few tens of $\mathrm{kHz}$ and are not a viable option therefore for QSW-ZVS operation. Alternatively to IGBTs, SiC MOSFET transistors can be used in this case to comply simultaneously with the voltage level and the switching frequency required by QSW-ZVS. The details of the $\mathrm{SiC}$ MOSFET used for the experimental verification are given in the next section (TABLE II). 


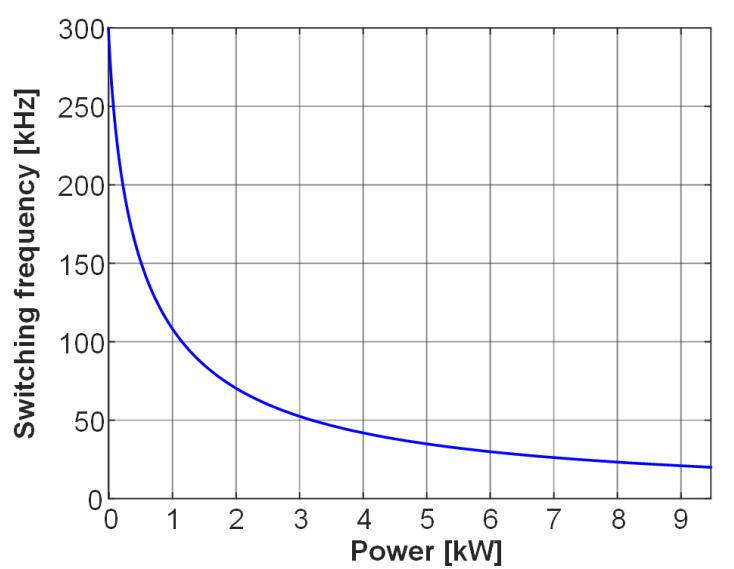

Fig. 7. Switching frequency vs. power for QSW-ZVS mode.

Two considerations must be made regarding the efficiency estimations. First, the inductance has been optimized for each operating mode, taking into consideration the core losses (hysteresis, eddy currents, etc.) and copper losses (conduction losses, proximity effect, fringing flux effects, etc.). Second, no switching frequency limitation has been considered for the QSW-ZVS (see Fig. 7). Obviously, this is not possible in practice, and the maximum switching frequency of the power devices must be respected. Once this limit is reached, the operation mode of the converter changes to TCM.

The estimated efficiencies are shown in Fig. 10. Both TCM and QSW-ZVS provide an efficiency of $97.5 \%$ at full load, thanks to the soft switching operation. As the load decreases, the efficiency in TCM mode decreases, being around 94\% at $2.5 \mathrm{~kW}$ ( $25 \%$ of the rated power). On the contrary, the efficiency for QSW-ZVS remains the same as for the full load condition. At very light loads (below $1.5 \mathrm{~kW}$ ), the differences in the efficiency for the two modes are even more relevant, being less than $90 \%$ for TCM vs. $98.5 \%$ for QSW-ZVS.

\section{EXPERIMENTAL RESULTS}

The theoretical derivations of the previous section have been experimentally validated using a prototype shown in Fig. 8. The design and optimization of the power converter cannot be approached as a simple replacement of $\mathrm{Si}$ by $\mathrm{SiC}$ devices. There are several critical issues which must be considered to take full advantage of $\mathrm{SiC}$ devices characteristics. Using ZVS techniques and SiC MOSFETs with low parasitic capacitances at high switching frequencies (up to $200 \mathrm{kHz}$ ) and high voltages $(800 \mathrm{~V})$ place relevant challenges. High values of $d v / d t$ must be carefully managed and careful design of the drivers (e.g. selection of the gate resistance, filtering control signals or especial layout, avoiding inductance loops) is required. The power transistor used for the experimental verification is a $\mathrm{SiC}$ MOSFET module CCS050M12CM2 (three half-bridge, six pack module) by Wolfspeed. It is noted that only a half-bridge is used. The module includes $\mathrm{SiC}$ diodes in parallel with the body diode of the MOSFETs to reduce the reverse recovery effect. The commercial driver CGD15FB45P1 by Wolfspeed is used. The control signals are sent from an FPGA to the driver using optic fibers.
The design of an inductor able to operate at high power over a wide range of switching frequencies (especially at high frequencies) is not trivial either. Core materials designed to operate at high switching frequencies are not able to manage very high powers. Three inductors of $600 \mu \mathrm{H}$ each are parallelized to obtain the $200 \mu \mathrm{H}$ required for the converter, with the peak current being around 50A (three parallel inductors are used instead of one mainly for practical reasons). The inductors are constructed using Litz wire and an ETD59-3F3 ferrite core.

Details of the experimental setup are summarized in TABLE II. Under TCM operation, the switching frequency is fixed at $20 \mathrm{kHz}$. In QSW-ZVS operation, the switching frequency increases as the load decreases, varying between $20 \mathrm{kHz}$ and $200 \mathrm{kHz}$. Examples of experimental waveforms for different operating conditions are shown in Fig. 9.

The efficiency in all the cases was measured once the converter temperature is stabilized. Heatsink with natural convection was used to dissipate the heat of the SiC MOSFETs. Input and output voltages and currents were measured using four calibrated digital multimeters (FLUKE 187). The calculated efficiencies are intended mainly for comparison purposes, as the prototype has not been optimized, and consequently the efficiency for both modes of operation could likely be improved. Fig. 10 shows the efficiency as a function of the power for TCM and QSW-ZVS modes.

The focus of the paper is the efficiency comparison at medium and light loads and as already discussed, for higher power levels both TCM and QSW-ZVS are expected to provide similar results. Fig. 10 shows the theoretical (up to full load, $10 \mathrm{~kW}$ ) and measured efficiencies (up to $60 \%$ of full load, $6 \mathrm{~kW}$ ), providing a good agreement between estimations and measurements. The larger error observed in the QSW-ZVS can be attributed to the simplicity of the power loss model used to calculate the inductance losses, as the effect of the variable switching frequency on the core losses was not considered.

It must be remarked that, efficiency using QSW-ZVS is higher than $97 \%$ in a power range which goes from $300 \mathrm{~W}(3.3 \%$ of full load) up to full load. On the contrary, the high efficiency of TCM with high loads ( $97 \%$ for $66 \%$ of full load) significantly reduces as the load level decreases.

TABLE II

MAIN SPECIFICATIONS FOR THE SYNCHRONOUS BOOST CONVERTER.

\begin{tabular}{cc}
\hline \hline Parameter & Value \\
\hline $\boldsymbol{V}_{\mathbf{1}} / \boldsymbol{V}_{\mathbf{2}}$ & $400 \mathrm{~V} / 800 \mathrm{~V}$ \\
\hline $\boldsymbol{P}_{\boldsymbol{M A X}}$ & $10 \mathrm{~kW}$ \\
\hline $\boldsymbol{f}_{\boldsymbol{s}}$ & $20 \mathrm{kHz}(\mathrm{nominal})$ \\
\hline $\boldsymbol{L}$ & $200 \mu \mathrm{H}$ \\
\hline $\boldsymbol{I}_{\boldsymbol{L} \boldsymbol{v}}$ & $-1.80 \mathrm{~A}$ \\
\hline \multirow{2}{*}{ MOSFET } & CCS050M12CM2 \\
\hline Driver & CGD15FB45P1 \\
\hline
\end{tabular}




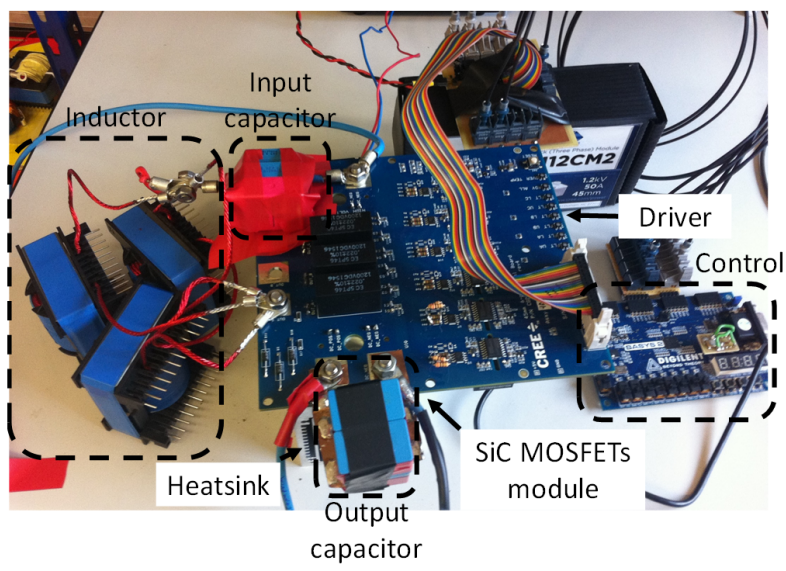

Fig. 8. Experimental prototype.
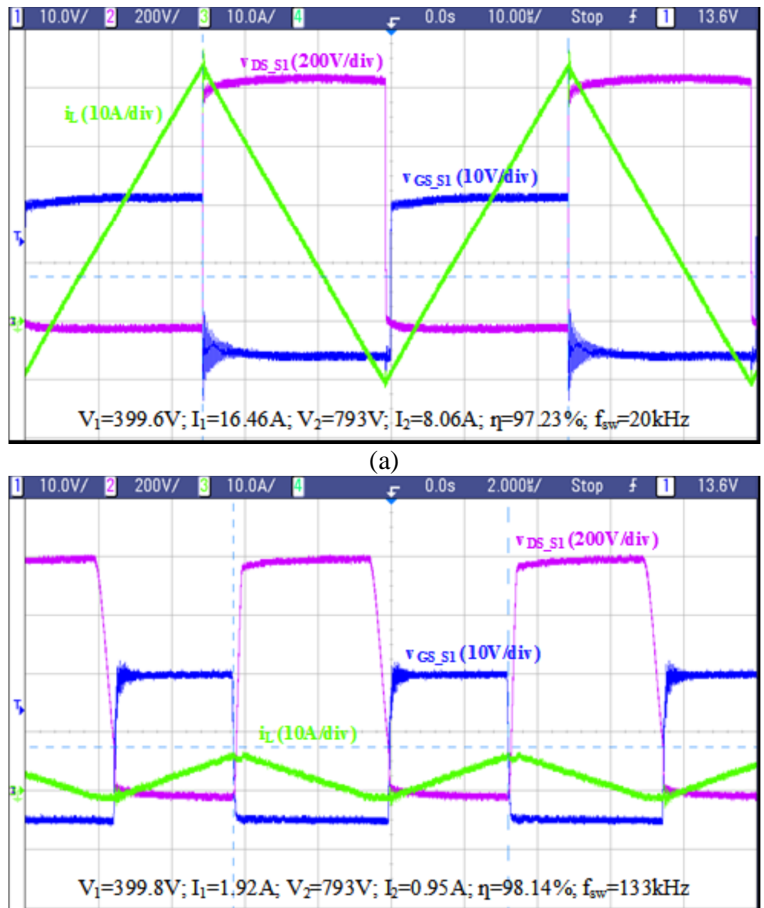

(b)

Fig. 9. Waveforms at (a) $65 \%$ of rated power and (b) $8 \%$ of rated power.

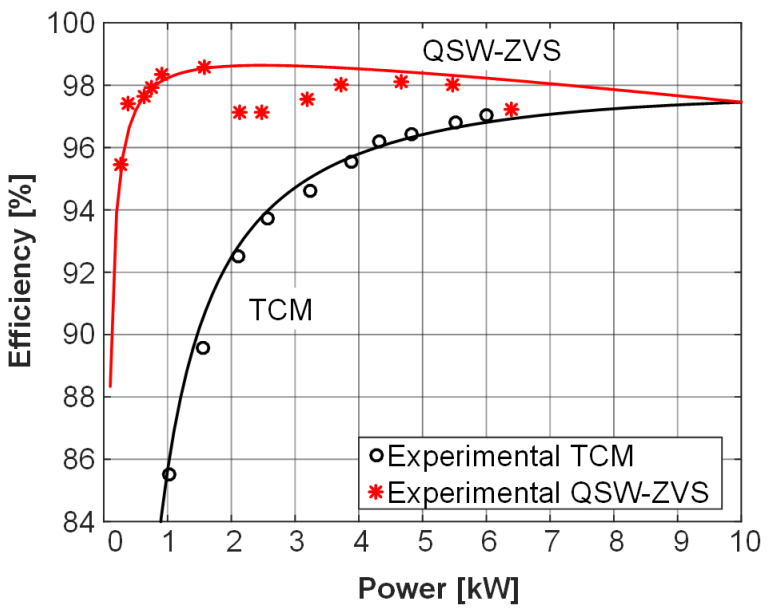

Fig. 10. Theoretical and experimental efficiency for TCM (o) and QSW-ZVS (*) modes
It is finally noted that while the efficiency at full load is usually the most important one, there are applications for which the efficiency at light load can also be critical. Averaged operating efficiencies, or weighted efficiencies, such as California Energy Commission (CEC) efficiency [37] or European (EURO) efficiency [38], [39], can be used in this case. TABLE III shows EURO and CEC efficiencies of the prototype using TCM and QSW-ZVS. These weighted efficiencies confirm the superior performance of QSW-ZVS over TCM.

TABLE III

EURO AND CEC EFFICIENCIES

\begin{tabular}{ccc}
\hline \hline Operation mode & EURO efficiency & CEC efficiency \\
\hline TCM & $95.093 \%$ & $96.033 \%$ \\
\hline QSW-ZVS & $97.704 \%$ & $97.450 \%$ \\
\hline
\end{tabular}

\section{CONCLUSIONS}

Three different modes of operation for a boost converter have been discussed in this paper: CCM, TCM and QSW-ZVS. For voltages above $400 \mathrm{~V}$, TCM is usually preferred over CCM, as it provides reduced switching losses. However, TCM penalizes efficiency at light loads.

The use of SiC MOSFETs, together with a variable switching frequency control technique (QSW-ZVS) have been used to improve the efficiency in a synchronous boost converter, especially at medium and light load (almost $98 \%$ at $5 \%$ of full load) operating at high voltage $(800 \mathrm{~V})$ and high frequency (up to $200 \mathrm{kHz}$ ). Increased efficiency at light loads can be relevant in battery chargers during the final stage of the charging process.

Si MOSFET can achieve the required switching frequencies, but have a voltage limit in the range of $600 \mathrm{~V}$. For higher voltages, IGBTs could be used but they cannot cope with the switching frequency requirements. WBG semiconductors, especially SiC MOSFETs, can simultaneously satisfy voltage and switching frequency requirements. It is therefore concluded that QSW-ZVS for the given specifications is not possible using Si power devices, and only becomes feasible if SiC MOSFETs are used. Experimental results using SiC MOSFETs have been provided to demonstrate the viability of the proposed concepts.

\section{REFERENCES}

[1] Ronan, E.R.; Sudhoff, S.D.; Glover, S.F.; Galloway, D.L., “A power electronic-based distribution transformer," in Power Delivery, IEEE Transactions on, vol.17, no.2, pp.537-543, Apr 2002

[2] van der Merwe, J.W.; du T. Mouton, H.; "The solid-state transformer concept: A new era in power distribution," AFRICON, 2009, pp.1-6, 2325 Sept. 2009

[3] Jih-Sheng Lai; Maitra, A.; Mansoor, A.; Goodman, F.; "Multilevel intelligent universal transformer for medium voltage applications," Industry Applications Conference, 2005. Fourtieth IAS Annual Meeting. Conference Record of the 2005, pp. 1893- 1899 Vol. 3, 2-6 Oct. 2005

[4] Xu She; Huang, A., "Solid state transformer in the future smart electrical system," in Power and Energy Society General Meeting (PES), 2013 IEEE , vol., no., pp.1-5, 21-25 July 2013

[5] J. Kolar and G. Ortiz, "Solid-state-transformers: key components of future traction and smart grid systems," in Proc. Of the International Power Electronics Conference (IPEC), Hiroshima, Japan, 2014 
[6] Falcones, S.; Xiaolin Mao; Ayyanar, R., "Topology comparison for Solid State Transformer implementation," Power and Energy Society General Meeting, 2010 IEEE, pp.1,8, 25-29 July 2010

[7] Advanced Power Converter for Universal and Flexible Power Management in Future Electricity Networks, UNIFLEX. FP6, EC Contract n: 019794 (SES6) EUROPEAN COMMISSION, DIRECTORATE J-ENERGY

[8] Zhao, T.; Wang, G.; Bhattacharya, S.; Huang, A. Q., "Voltage and Power Balance Control for a Cascaded H-Bridge Converter-Based Solid-State Transformer," Power Electronics, IEEE Transactions on , vol.28, no.4 pp.1523,1532, April 2013

[9] Xu She; Lukic, S.; Huang, A.Q.; Bhattacharya, S.; Baran, M.; , "Performance evaluation of solid state transformer based microgrid in FREEDM systems," Applied Power Electronics Conference and Exposition (APEC), 2011 Twenty-Sixth Annual IEEE, pp.182-188, 6-11 March 2011

[10] Shojaei, A.; Joos, G., "A topology for three-stage Solid State Transformer," in Power and Energy Society General Meeting (PES), 2013 IEEE, pp.1-5, 21-25 July 2013

[11] Briz, F.; Lopez, M.; Rodriguez, A.; Zapico, A.; Arias, M.; Diaz- Reigosa, D., "MMC based SST," in Industrial Informatics (INDIN), 2015 IEEE 13th International Conference on, pp.1591-1598, 22-24 July 2015

[12] A. Lesnicar, and R. Marquardt, "An Innovative Modular Multilevel Converter Topology Suitable for a Wide Power Range", IEEE PowerTech Conference. June 23-26, 2003.

[13] M. Glinka and R. Marquardt, "A New AC/AC Multilevel Converter Family”, IEEE Transactions on Industrial Electronics, vol. 52, n. 3. June 2005.

[14] A. Lesnicar, and R. Marquardt, "A new modular voltage source inverter topology", EPE 2003, Toulouse, France. Sept. 2-4, 2003.

[15] Peftitsis, D.; Tolstoy, G.; Antonopoulos, A.; Rabkowski, J.; Lim, JangKwon; Bakowski, M.; Angquist, L.; Nee, H-P, "High-power modular multilevel converters with SiC JFETs", Energy Conversion Congress and Exposition (ECCE), p. 2148-155, 12-16 Sept. 2010.

[16] J. Rodriguez, J.-S. Lai, and F. Z. Peng, "Multilevel inverters: A survey of topologies, controls, and applications" IEEE Trans. Ind. Electron., vol. 49, n. 4, p. 724-738. Ago. 2002.

[17] Rohner, S.; Bernet, S.; Hiller, M.; Sommer, R.; "Analysis and Simulation of a $6 \mathrm{kV}, 6$ MVA Modular Multilevel Converter", IEEE Industrial Electronics Conference (IECON). p. 225-230, 3-5 Nov. 2009.

[18] K. Young, C. Wang, L. Y. Wang and K. Strunz, "Chapter 2 - Electric Vehicle Battery Technologies," in Electric Vehicle Integration into Modern Power Networks, New York, Springer New York, 2013, pp. 15 56.

[19] José Millán; Philippe Godignon; Xavier Perpiñà; Amador Pérez-Tomás; José Rebollo, "A survey of wide bandgap power semiconductor devices", in Power Electronics, IEEE Transactions on, vol.29, no.5, May 2014

[20] Vasiladiotis, M.; Rufer, A., "Analysis and Control of Modular Multilevel Converters With Integrated Battery Energy Storage," Power Electron., IEEE Trans. on , vol.30, no.1, pp.163,175, Jan. 2015

[21] M. A. Perez, D. Arancibia, S. Kouro and J. Rodriguez, "Modular multilevel converter with integrated storage for solar photovoltaic applications," Industrial Electronics Society, IECON 2013 - 39th Annual Conference of the IEEE, Vienna, 2013, pp. 6993-6998.

[22] R. Abhinav and N. M. Pindoriya, "Grid integration of wind turbine and battery energy storage system: Review and key challenges," 2016 IEEE 6th International Conference on Power Systems (ICPS), New Delhi, 2016, pp. 1-6.

[23] A. F. Burke, "Batteries and Ultracapacitors for Electric, Hybrid, and Fuel Cell Vehicles," Proceedings of the IEEE, vol. 95, no. 4, pp. 806-820 April 2007

[24] J. Miller, "Energy storage system technology challenges facing strong hybrid, plug-in and battery electric vehicles," Vehicle Power and Propulsion Conference, 2009. VPPC '09. IEEE, pp. 4-10, Sept. 2009.

[25] Yang, L.; Zhang, Y.; Lee, C.Q., "A family of constant-switchingfrequency quasi-square-wave converters," Electrical and Computer Engineering, 1993. Canadian Conference on, pp.309,312 vol.1, 14-17 Sep 1993.

[26] Yang, L.; Zhang, Y.F.; Lee, C.Q., "Analysis of the boost constantfrequency quasi-square-wave converters," Circuits and Systems, 1994., Proceedings of the 37th Midwest Symposium on, vol.2, pp.1172,1175 vol.2, 3-5 Aug 1994.
[27] Maksimovic, D., "Design of the zero-voltage-switching quasi-squarewave resonant switch," Power Electronics Specialists Conference, 1993. PESC '93 Record., 24th Annual IEEE, pp.323,329, 20-24 Jun 1993.

[28] C. Marxgut, J. Biela and J. W. Kolar, "Interleaved Triangular Current Mode (TCM) resonant transition, single phase PFC rectifier with high efficiency and high power density," Power Electronics Conference (IPEC), 2010 International, Sapporo, 2010, pp. 1725-1732.

[29] Vorperian, V., "Quasi-square-wave converters: topologies and analysis," Power Electronics, IEEE Transactions on , vol.3, no.2, pp.183,191, Apr 1988.

[30] Andreassen, Pal; Undeland, T.M., "Digital Control Techniques for Current Mode Control of Interleaved Quasi Square Wave Converter," Power Electronics Specialists Conference, 2005. PESC '05. IEEE 36th, pp.910,914, 16-16 June 2005.

[31] Costa, J.M.F.D.; Silva, M.M., "Small-signal models and dynamic performance of quasi-square-wave ZVS converters with voltage-mode and current-mode control," Circuits and Systems, 1995., Proceedings., Proceedings of the 38th Midwest Symposium on, vol.2, no., pp.1183,1188 vol.2, 13-16 Aug 1995.

[32] Jong-Bok Baek; Woo-In Choi; Bo-Hyung Cho, "Digital Adaptive Frequency Modulation for Bidirectional DC-DC Converter," Industrial Electronics, IEEE Transactions on, vol.60, no.11, pp.5167,5176, Nov. 2013.

[33] Yousefzadeh, V.; Babazadeh, A.; Ramachandran, B.; Alarcon, E.; Pao, L.; Maksimovic, D., "Proximate Time-Optimal Digital Control for Synchronous Buck DC-DC Converters," Power Electronics, IEEE Transactions on, vol.23, no.4, pp.2018,2026, July 2008.

[34] Knecht, O.; Bortis, D.; Kolar, J.W., "Comparative Evaluation of a Triangular Current Mode (TCM) and Clamp-Switch TCM DC-DC Boost Converters," Energy Conversion Congress and Exposition (ECCE 2016, IEEE), pp., 18-22 September 2016.

[35] R.W. Erickson, D. Maksimovic, "Fundamentals of Power Electronics", 2ed. Springer Science+Business, 2001.

[36] M. Kasper, R. M. Burkart, G. Deboy and J. W. Kolar, "ZVS of Power MOSFETs Revisited," in IEEE Transactions on Power Electronics, vol. 31, no. 12, pp. 8063-8067, Dec. 2016

[37] C. W. C. E. C. B. Brooks, "Guideline for the use of the Performance Test Protocol for Evaluating Inverters Used in Grid-Connected Photovoltaic Systems," $2005 . \quad$ [Online]: http://www.gosolarcalifornia.ca.gov/equipment/documents/Sandia_Guid eline_2005.pdf. [Last accessed: Jan. 2017].

[38] EC 1275/2008 Regulation of 2005/32/EC, EcoDesign. European

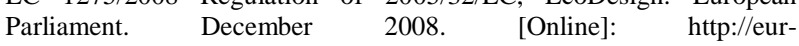
lex.europa.eu/eli/reg/2008/1275/oj. [Last accessed: Jan. 2017].

[39] EC 278/2009 Regulation of 2005/32/EC, EcoDesign. European $\begin{array}{llll}\text { Parliament. } & \text { April } & \text { 2009. } & \text { [Online]: }\end{array}$ http://data.europa.eu/eli/reg/2009/278/oj. [Last accessed: Jan. 2017].

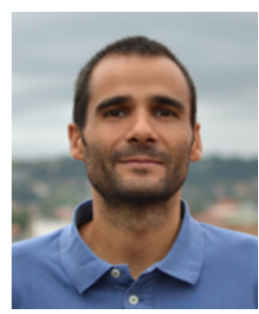

Alberto Rodriguez (S'2007, M'2014) was born in Oviedo, Spain, in 1981. He received the M.S. degree in telecommunication engineering in 2006 from the University of Oviedo, Gijón, Spain, and the Ph.D. degree in electrical engineering in the same university in 2013. Since 2006, he has been a researcher with the Power Supply System Group and an Assistant Professor with the Department of Electrical and Electronic Engineering at the University of Oviedo. His research interests are focused on multiple ports power supply systems, bidirectional DC-DC power converters and wide band gap semiconductors.

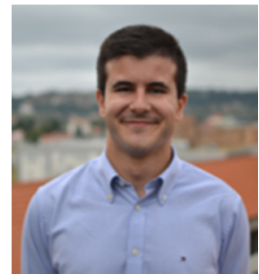

Aitor Vazquez (S'2010, M'2015) was born in Oviedo, Spain, in 1984. He received the M.Sc. degree in telecommunication engineering, in 2009, and the $\mathrm{Ph} . \mathrm{D}$. degree in electrical engineering in 2016, from the University of Oviedo, Gijon, Spain. Since 2010 he has been a researcher with the Power Supply System Group and an Assistant Professor with the Department of Electrical and Electronic Engineering at the University of Oviedo. His current research interests include modularization techniques applied to bidirectional dc-dc converters for $\mathrm{HEV}$, battery management power supplies, DC distribution grids, power factor corrector ac-dc converters and energy recovery systems. 


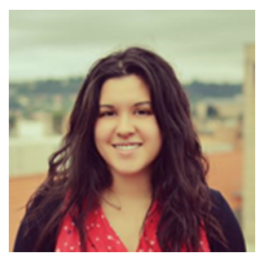

Maria R Rogina (S'2014) was born in Aviles, Spain, in 1990. She received the M.Sc. degree in

telecommunication engineering from the University of Oviedo, Spain, in 2014, and she is currently pursuing the $\mathrm{Ph} . \mathrm{D}$. degree in the same university. Her research interests include switching-mode power supplies, dc$\mathrm{dc}$ converter modelling and bidirectional DC-DC power converters.

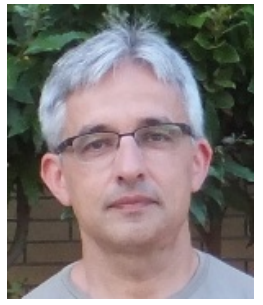

Fernando Briz (A'96-M'99-SM'06) received the M.S. and Ph.D. degrees from the University of Oviedo, Gijón, Spain, in 1990 and 1996, respectively. He is currently a Full Professor with the Department of Electrical, Computer and Systems Engineering, University of Oviedo. His topics of interest include electronic power converters and ac drives, power systems, machine monitoring and diagnostics and digital signal processing.

Dr. Briz received the 2005 IEEE TRANSACTIONS ON INDUSTRY APPLICATIONS Third Place Prize Paper Award and was the recipient of eight IEEE Industry Applications Society Conference and IEEE Energy Conversion Congress and Exposition prize paper awards. He is currently Publications Chair and Associate Editor of the Industrial Drives Committee of the IAS-IPCSD. 